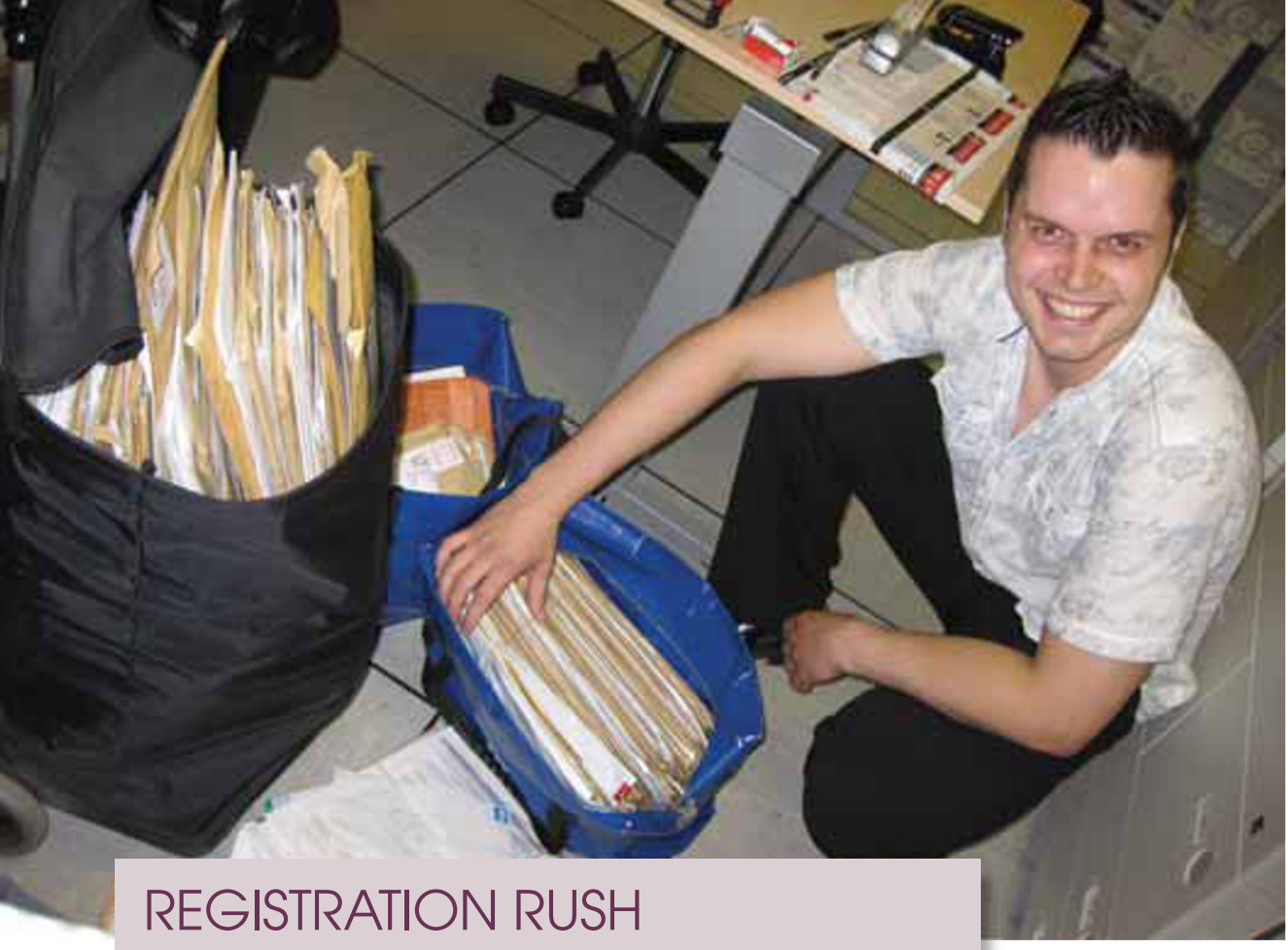

The GDC's London offices stayed open until midnight on July 30 to receive last minute applications from dental nurses and dental technicians determined to meet the deadline for registering on the basis of experience. At the time of the deadline 36,225 dental nurses and 6,381 dental technicians were registered and some 5,000 applications were still to be processed. Victor Oelofse (pictured), facilities and IT administrator, was on hand to help.

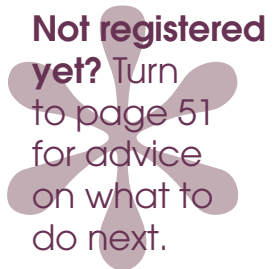

\title{
DCP DEGREE LAUNCHED
}

A degree aimed exclusively at DCPs, the BSc in primary dental care, is starting this month at the University of Kent.

Led by Debbie Reed, former principal tutor at the army school of dental nursing, the course can be completed in three years full-time or six years part-time. Topics include: radiography, communication within teams, research, nutrition and the development of the General Dental Council. Participants will also be required to write a dissertation.

The modular course involves 120 hours of contact teaching a year, plus 1,080 hours of work-based and distance learning. Participants have to be registered with the GDC and employed in primary dental care. Students who complete two years of the course will be eligible for a diploma in primary dental care. The course is based at the university's Medway campus.

Debbie Reed, lecturer in primary care dentistry, and an examiner for the National

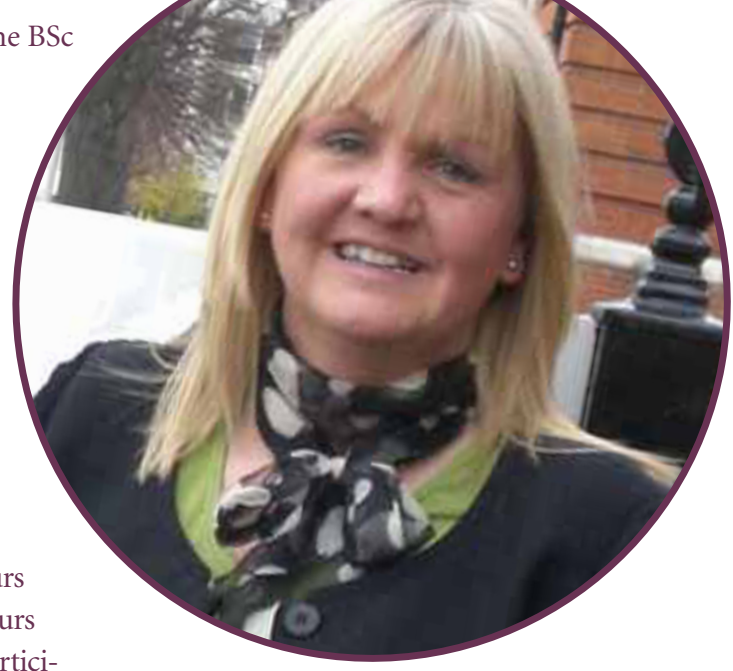

Examining Board for Dental Nurses, said: 'The programme seeks to equip dental care workers for longer and more rewarding careers. Through a mix of greater professional and academic development, we hope to keep people interested and motivated in their jobs for the long-term.'

\section{ARE YOU A WORLD CLASS HYGIENIST?}

Applications are invited for the 2010 World Dental Hygienist Awards, which are offering $£ 5,000$ in prize money. The winner of the research category will receive

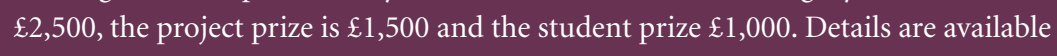

